\title{
A Reference Model for Mobile Social Software for Learning
}

Citation for published version (APA):

De Jong, T., Specht, M., \& Koper, R. (2008). A Reference Model for Mobile Social Software for Learning. International Journal of Continuing Engineering Education and Lifelong Learning (IJCEELL), 18(1), 118-138. https://doi.org/10.1504/IJCEELL.2008.016079

\section{DOI:}

10.1504/IJCEELL.2008.016079

Document status and date:

Published: 01/01/2008

Document Version:

Peer reviewed version

Please check the document version of this publication:

- A submitted manuscript is the version of the article upon submission and before peer-review. There can be important differences between the submitted version and the official published version of record. People interested in the research are advised to contact the author for the final version of the publication, or visit the DOI to the publisher's website.

- The final author version and the galley proof are versions of the publication after peer review.

- The final published version features the final layout of the paper including the volume, issue and page numbers.

Link to publication

\section{General rights}

Copyright and moral rights for the publications made accessible in the public portal are retained by the authors and/or other copyright owners and it is a condition of accessing publications that users recognise and abide by the legal requirements associated with these rights.

- Users may download and print one copy of any publication from the public portal for the purpose of private study or research.

- You may not further distribute the material or use it for any profit-making activity or commercial gain

- You may freely distribute the URL identifying the publication in the public portal.

If the publication is distributed under the terms of Article 25fa of the Dutch Copyright Act, indicated by the "Taverne" license above, please follow below link for the End User Agreement:

https://www.ou.nl/taverne-agreement

Take down policy

If you believe that this document breaches copyright please contact us at:

pure-support@ou.nl

providing details and we will investigate your claim.

Downloaded from https://research.ou.nl/ on date: 26 Apr. 2023 


\title{
A reference model for mobile social software for learning
}

\section{Tim de Jong*, Marcus Specht and Rob Koper}

Educational Technology Expertise Centre, Open University of the Netherlands, Valkenburgerweg 177, NL-P.O. Box 2960, 6401DL Heerlen, The Netherlands

E-mail: tim.dejong@ou.nl

E-mail: marcus.specht@ou.nl

E-mail: rob.koper@ou.nl

*Corresponding author

\begin{abstract}
This paper provides a reference model for mobile social software and uses it to analyse the current state-of-the-art in its applications for learning. A general overview of the literature in the field and the available projects will be given. The reference model for mobile social software helps us to (1) find out to what extent mobile social software for learning has already been used until date, (2) identify gaps and limitations in current research and provide new ideas and innovative approaches for learning based on these gaps, and (3) position our current research work in preparation of a study of applications of mobile social software for learning. After describing the current state-of-theart, its limitations and suggestions for future research, an implemented solution of mobile social software for learning is briefly described. The paper concludes with an outlook on possible chances and challenges for future research.
\end{abstract}

Keywords: mobile learning; mobile social software; literature review.

Reference to this paper should be made as follows: de Jong, T., Specht, M. and Koper, R. (2008) 'A reference model for mobile social software for learning', Int. J. Cont. Engineering Education and Lifelong Learning, Vol. 18, No. 1, pp.118-138.

Biographical notes: Drs. Tim de Jong is a PhD student at the Open University of the Netherlands. He received his Master's degree in Knowledge Engineering from the University of Maastricht in 2005. The topic of his current research and his main research interests are mobile learning, contextualised computing and knowledge engineering. Moreover, he is currently working in the European eContentplus project MACE, which focuses on the metadata enrichment of architectural content.

Dr. Marcus Specht is an Associate Professor at the Open University of the Netherlands. He received his Diploma in Psychology in 1995 from the University of Trier and in 1998 in Adaptive Learning Technology. His main research interests are adaptive learning and training systems, knowledge management, contextualised computing and intelligent interfaces. $\mathrm{He}$ coordinated the technical development of a highly scalable e-Learning platform for design and architecture in the European WINDS project and was involved in the LISTEN project on audio-augmented environments. Currently, he is the coordinator of the European project RAFT on field trip support for mobile collaboration and the work package coordinator for personalised learning tools in the European Network of excellence PROLEARN. 


\begin{abstract}
Professor Dr. Rob Koper holds a PhD in Educational Technology from the Open University of the Netherlands (OUNL), The Netherlands. Since 1998 he has been a full professor in educational technology, specifically in e-Learning technologies. As a Director of RTD into learning technologies he was, among other responsibilities, responsible for the development of Educational Modelling Language (the predecessor of IMS Learning Design). He led the OUNL's contribution to the IMS LD specification activities. His research focuses on self-organised distributed learning networks for lifelong learning, including RTD into software agents, educational semantic web, interoperability specifications and standards.
\end{abstract}

\title{
1 Introduction and background
}

The recent uptake of mobile devices has made access to personal social networks available nearly anywhere, anytime and anyplace (Rheingold, 2002; Castells et al., 2007). Mobile messaging can be considered as one of the first 'killer applications' for mobile devices that has already been introduced several years ago. Different studies have demonstrated the new possibilities of messaging and their potential for learning support as for inclusion, engagement and mobile support (Riordan and Traxler, 2005; Mitchell et al., 2006). In recent studies, the impact of this new technology on communication and learning in the younger generation is described as highly relevant for new forms of learning support (Green and Hannon, 2007). With the introduction of new multi-faceted mobile devices, the latest research aims at the potential of mobile content creation and sharing, personalised and contextualised services or sensebased and contextualised human-computer interaction. Additionally, with the current trends in social software and new types of contextualised mobile technology like presence sharing, contextualised messaging (www.jaiku.com), or sensor data sharing (http://www.apple.com/de/ipod/nike/run.html), technology is coming to end users from which the authors expect to have great potential for everyday learning support.

Social software has its roots in research on Groupware and Computer-Supported Cooperative Work (Greif and Sarin, 1986; Cockburn and Thimbleby, 1991; Grudin, 1994). Anderson (2005) states that social software has several applications and characteristics that can prove useful for learning support: presence tools, notification, filtering, cooperative learning support, referring, student modelling, introducing learners to each other, helping others and finally documenting and sharing constructed objects.

Especially, educational blogs have recently become a popular way of collecting personal information and learning experiences (Oravec, 2002) and combine this with reflection in a community. Mobile blogging as a mobile application for blogging provides an instant way of accessing and collecting personal memories. Mobile blogging applications for personal reflection or community building have been researched in research projects in undergraduate and higher education (RAMBLE Project, 2006; Specht and Kravcik, 2006).

In context-aware computing, a variety of notions of context has been discussed and automatic possibilities for context detection, context matching, and sensors and tagging for context have been researched (Abowd and Mynatt, 2000; Dey and Abowd, 1999). Context-aware computing together with ubiquitous and pervasive techniques can result in systems that adapt to user's identity, preferences, location, environment and time 
(Gross and Specht, 2001; Zimmermann et al., 2005b; Specht and Kravcik, 2006). For identifying and tagging in context-aware systems, a variety of new technologies is currently developed. Classical tagging approaches for objects found in, for example, early museum-guiding applications (Oppermann and Specht, 2000) are nowadays again a hot topic with technologies, such as radio frequency identification (RFID) tagging, that are already available or built into mobile devices.

In that sense mobile social software allows for the contextualisation to the individual's social and physical environment and enables new forms of learning support, including: ubiquitous multimodal notification, ubiquitous multimodal messaging, ubiquitous content exchange and sharing, contextualisation services or physical world tagging. Furthermore, lifelong learning approaches in learning networks (Koper, 2005), which investigate the support of informal learning activities and the integration with formal learning, may benefit from these new kinds of technologies and their possibilities for embedding learning experiences in everyday life.

The strengths of embedding learning support in authentic learning contexts have been argued for quite some time in the educational literature (Wenger and Lave, 1991). Combining the strengths of both mobile and context-aware systems and applying them to educational systems can lead to contextualised learning support by utilising information about the learner's environment and adapting the learning content to that information, as described in Zimmermann et al. (2005a). From a pedagogical point of view, the concepts of reflection in action and reflection about action (Schön, 1983; Schön, 1987; Wenger and Lave, 1991), and embedding learning support into communities of practice are the basis of new approaches in mobile and social learning software (Bo, 2002; Specht, 2006; Specht and Kravcik, 2006).

Recent studies on mobile learning have shown that already a variety of best practices and approaches for using mobile devices to support learners is being applied, nevertheless most of them are proprietary solutions lacking a sound pedagogical approach and conceptualisation and also an open and flexible underlying infrastructure (Tatar et al., 2003; Naismith et al., 2004). In addition to that, several challenges for collaborative infrastructures for collaborative work environments are presented in LasoBallesteros (2006). Among the challenges identified are: activity-oriented context-aware collaboration features provided by the collaborative infrastructure supporting human interactions, pervasive collaboration support and heterogeneous devices with embedded collaboration capabilities. Context-aware mobile devices providing communication and collaboration features could provide a solution for these challenges (Lundin and Magnusson, 2002).

\section{Mobile social learning in context}

Recently, Sharples et al. (2007) in their theory of mobile learning stressed the importance of conversations for learning. Conversations, they argue, are a key element for constructing knowledge in collaborative tasks. Related to that, Wenger and Lave (1991) have stressed the importance of collaborative learning and embedding the learner in communities of practice. With the increasing mobility of people and the possibilities of ubiquitous information access, the role of mobile devices in supporting learning also increases. Moreover, mobile access to online learning communities and social networks 
would simplify user participation in and awareness about learning processes in a community.

Additionally, still most social interactions take place in a real-world context and the application of mobile devices supporting these interactions would provide opportunities for an increasingly efficient community building, for example, turning an accidental encounter into a learning moment. Already, social software in online environments tries to employ the power of communities for more efficient or more knowledgeable information processing. In that sense, Anderson (2005) has also emphasised the importance of social software for learning. Additionally, Knight (2005) highlights the importance of situated learning support by defining learning as a social practice in which learners develop their identity through participation in specific communities and practices. Mobile social software offers a learner the opportunity to become part of a learning community and at the same time enables learning in authentic contexts. From the author's point of view, mobile social software applications combine virtual and real-world support for social interactions and collaboration in a real-world context.

The importance of mobile social software for learning has also been supported by recent research in a review of mobile technologies for learning. Nesta FutureLabs (Naismith et al., 2004) described the underpinning of current mobile learning approaches by common learning paradigms. Moreover, in Stead (2005) findings are presented that learning works best for a learner and tutor if the mobile devices are combined with group activities or other media. Additionally, learners themselves seem to be enthusiastic about using the mobile devices for collaboration and communication. For example, Smordal et al. (2002) found out that students were using the mobile devices as a communication tool. The project concluded that the mobile devices used should be seen as 'potential gateways in complicated webs of interdependent technical and social networks'.

To support this opinion about the importance of mobile social software for learning, a review of the current state-of-the-art in the field will be presented in this paper. As a basis for this review, the next section will present a classification of mobile social software for learning for a number of reasons. Firstly, during classification a reference model is derived that also can be used as a basis for future application of mobile social software in the context of learning. Secondly, the classification should help to find out to what extent social software for mobile learning has already been used to this date. Thirdly, a categorisation helps us to identify gaps in current mobile social software research and provide ideas for new community-based mobile learning software based on these gaps. Fourthly, by considering mobile social software in general, we hope to find mobile social software that can be applied in innovative approaches for learning. Finally, the state-ofthe-art presented here will help us to position our current research work in preparation of several empirical studies and development of mobile social software for learning.

\section{A classification of mobile social software for learning}

As the research in mobile social software has a background in context aware and ubiquitous computing as well as mobile learning research and social software, the authors have considered different classification schemes from those backgrounds. Basically in our classification we apply the following: content, context, purpose, information flow and pedagogical model. The classification was applied on the literature, which mostly 
consisted of the papers of two major conferences in the field of mobile learning since the year 2002: MLEARN and WMTE.

\subsection{Content - describes applications based on the artefacts exchanged and shared by users}

A framework for analysing the features of mobile learning as well as mobile learning systems is given in Sharples et al. (2007), where the authors distinguish between a semiotic layer, for analysing mobile learning from the learner's viewpoint, and a technology layer for describing mobile learning from a technology perspective. For both layers, the framework describes the same concepts: mediating artefacts, subject, object, control, context and communication; the specific meaning of a concept, however, depends on the selected layer. For example, the control dimension can describe either human-computer interaction or social rules for technology or semiotic layers, respectively. Furthermore, in the learning process the learner uses mediating artefacts and objects. First, to analyse the mediating artefacts from a technological perspective, the classification needs to analyse the mobile learning technology used, more specifically to analyse the kind ubiquitous and pervasive system. The semiotic perspective identifies the learning resources, the object and environment in which the learning is carried out. In our analysis of the literature, the learning resources, we mainly found, were annotations, documents, messages and notifications.

The MOBILearn project (Bo, 2002) combines multimedia content creation, content delivery and stores context metadata about that content. Interestingly, the KLIV project (Brandt et al., 2002; Brandt and Hillgren, 2003) delivered video content to Personal Digital Assistants (PDAs) used by nurses and demonstrated the importance of the fact that the content was created by the same user community even if the creation and the usage of content were strictly separated. Another system that provides functionality for content delivery is xTask (Ketamo, 2002). xTask adds the collaborative editing of content and instant messaging for discussing the content to foster more dynamic content production in collaborative distributed settings. Environmental Detectives (Klopfer et al., 2002) is an example that along with content creation stores location metadata for the content created; students take pictures in an outside setting to enhance the learning experience in remote participation. A similar approach was taken in the RAFT project, which demonstrated effects on classroom engagement and participation with the integration of authentic learning materials from remote field trips (Bergin et al., 2007).

Mobile social software for content creation often also allows for making annotations. A specific example is C-notes (Milrad et al., 2002), a solution for users to create textual notes to annotate classroom presentations. The notes are created using a PDA or a special pen to scan text and are stored in a group archive for later access or exchange with other users. Along with each note some metadata such as author, date and keywords can be stored. PhotoStudy (Joseph et al., 2005) annotates content with images or audio recorded on mobile devices. Likewise, mobile Collaborative Learning Tool (mCLT) (Arrigo et al., 2004) is also aimed at note taking, but adds e-mail or SMS communication to enable users to instantly create and share live data and annotations. A slightly different approach is presented in Jansen et al. (2005) that delivers content on a public display board called SynchroBoard; most of the information on the board is public information, but is adapted to individual users based on Bluetooth information from their mobile phones. This enables personal perspectives on public content objects. 
Among the mobile social software considered a range of communication tools are found, providing several different communication channels. For instance, the HandLeR project by Sharples et al. (2002) supports direct voice communication, whereas Silander et al. (2004) provide text-based communication via an instant messaging tool. Conversely, the Musex system (Yatani et al., 2004) does not provide the means of communication itself but focuses on enkindling face-to-face discussion. It does this by using paired PDAs to inform two coupled learners about the correctness of their answers to a certain question.

The WELCOME mobile client, described in Berger et al. (2003), sends SMS notifications to university students whenever new material or new postings have been added to the university's e-Learning system. Furthermore, invitations to private learning groups are also sent by SMS notification. Likewise, Silander et al. (2004) present a system that sends notifications about whether or not content has been added to a shared knowledge map. Liu et al. (2005) describe the use of SMS messages to inform students about the collaborative activities of their peers. In most systems, notifications are used to notify either about nearby people with matching interests (Eagle and Pentland, 2005) or someone about the current activity of other persons.

\subsection{Context - describes applications based on the context parameters taken into account for learning support}

The context dimension describes the kind of contextual information that is used in the system; contextual information can be used to describe or derive information about the user (describing, for example, the learner's personal preferences), information about the environment (describing the learner's physical environment), or information about the social context of the learner (describing the social relationships a learner is involved in and the social networks the learner is part of). In community systems, the context describes where a user is located within the community (boundary, centre) and the number and kind of relations this user has with other users within the community. In context-aware computing, a variety of notions and interpretations have developed over the years. Zimmermann et al. distinguish between definitions by synonym or definitions by example which mainly name and describe certain context parameters as location, identity, time, temperature, noise, as well as beliefs, desires, and commitments and intentions (Zimmermann et al., 2007). Furthermore, they introduce an operational definition of context describing the following main categories of the context information:

- Individuality context includes information about objects and users in the real world as well as information about groups and the attributes or properties the members have in common.

- Time context, basically this dimension ranges from simple points in time to ranges, intervals and a complete history of entities.

- Locations context is divided into quantitative and qualitative location models, which allow to work with absolute and relative positions.

- Activity context reflects the entities goals, tasks and actions.

- Relations context captures the relation an entity has established to other entities, and describes social, functional and compositional relationships. 
In our analysis, several possible types of context filters were identified including identity/individuality, time, location, environment/activity and social/relations context. Eagle and Pentland (2005) describe a system that sends notifications based on identity information in user profiles and proximity information derived from a mobile phone's Bluetooth transmitter. The notifications are used to increase serendipity in social relationships and to inform users about nearby users with similar interests.

Identity context is often also combined with other forms of context. One specific example of such a combination is given by Ogata and Yano (2004b) who present 'Collaborative Learning support system with a Ubiquitous Environment' (CLUE), a system for learning English in real-world situations. CLUE uses (1) a learner profile to adapt the learning content to the learner's interest and (2) location information to link objects/locations to suitable English expressions, i.e. appropriate learning content. Likewise, Bo (2002) combines a user profile and user position, to facilitate personalised and location-based information delivery. AwarePhone (Bardram and Hansen, 2004) uses several context-parameters at the same time. First of all, location is used to locate fellow employees within the hospital. Second, a calendar artefact is used to capture and share time context and also indicates the activity of a user at a certain moment. The activity is furthermore given by a shared status message. The combination of these three context parameters leads to what the authors call 'context-mediated social awareness'.

Environmental context information is used in several systems, most notably QueryLens (Konomi, 2002) which focuses on information sharing using smart objects. Moreover, the TAco Next Generation Object (TANGO) system (presented by Ogata and Yano, 2004a) and the Musex system (Yatani et al., 2004) detect objects in the vicinity by using RFID tags. Moop (Mattila and Fordel, 2005) couples a Global Positioning System (GPS) location to observations/information gathered in the field for later analysis in the classroom. Wallop (Farnham et al., 2004) allows its users to discover social relationships and provides social awareness by storing and analysing social context information; to derive the social context communication patterns, system interactions and co-occurrence information were analysed.

\subsection{Purpose - describes applications according to the goals and methods of the system for enabling learning}

Richter and Koch (2007) define three main purposes of social software: identity management, information sharing and relationship management. Hence, social software applications can be described according to their focus on information management (Wikis, Blogs), identity management (Weblogs, Portfolio Systems), and relationship management (Networking Platforms, IM Applications). In combination with learning, Anderson (2005) identifies several different purposes for social software: presence tools, notification, filtering, cooperative learning support, referring, student modelling, introducing learners to each other, helping others, and finally documenting and sharing constructed objects.

A main purpose found in social software systems for learning support is sharing content and knowledge among a community of users. Interactive Logbook, presented in Bull et al. (2004) and Chan et al. (2005), is a shared workspace system supporting mobile learning with mobile access to documents and handwritten editing of content. A variety of learning management systems extend their basic functionality with services and software for mobile access (Bo, 2002; Vavoula and Sharples, 2002; Houser and 
Thornton, 2005). Besides the sharing of content, some approaches also provide facilities for the collaborative annotation of content and note-taking, where personal messages can be attached to the learning content to facilitate personal or community reflection, as for example in C-notes (Milrad et al., 2002).

One of the most popular classroom scenarios is a mobile social tool that facilitates discussion and brainstorming. Mobile notes (Bollen et al., 2006) facilitates brainstorming and discussion via different kinds of annotations and voting. Ng'ambi (2005) presents a shared knowledge approach called DFAQ - a mobile social system for Dynamic Frequently Asked Questions. Yet another kind of solution aims at collaborative concept mapping, for instance PerkamII - a knowledge awareness map for sharing knowledge, collaborating and sharing individual experiences (El-Bishouty et al., 2006). PerkamII and QueryLens (Konomi, 2002) additionally use real-world objects tagged with RFID to interact with real-world contexts. Mobile recommender systems like MovieLens Unplugged (Miller et al., 2003) give access to community-generated metadata about movies, enable instant connection to real-world objects, and develop a community rating and review of the described movies.

Another group of systems mainly aims at social awareness. Several different types of awareness can be identified. Nova et al. (2005) have researched the impact of location awareness on collaborative task performance. Another example for a technical solution of location-based campus support has been given in Ferscha et al. (2001). A related but more extensive system is presented in Eagle and Pentland (2005), which combines location and interest-based awareness, and should increase serendipity. In this example, location is coupled to a similarity in user profiles to notify people when someone with similar interests is nearby. Messeguer et al. (2006) describe a system that uses location information in a classroom for group awareness and identification group structure. Conversely, Kajita and Mase (2006) bring forward a classroom system that makes the teacher aware of current problems and progress of students. Furthermore, Bardram and Hansen (2004) describe AwarePhone, a system for activity awareness in a hospital. AwarePhone displays the current activity of a doctor and can be used by nurses to find out an appropriate moment to interrupt him or her.

Another purpose is to guide communication and provide a central place for it. An example is given by Farnham et al. (2004) with their Wallop system designed for maintaining and extending of a user's social network; it provides a central place for people to contact each other. Additionally, most of these communication systems try to bridge the gap between geographically dispersed people to include them in collaborative processes. Raymond et al. (2005) present a synchronous communication application (instant messaging, audio and video conferencing) that also provides collaboration facilities like a white board. Similarly, the HandLeR project (Sharples et al., 2002) offers conversation between mobile learners to support knowledge sharing between them and teachers, experts and peers.

Mobile collaborative games are good examples for enhanced engagement and immersion of users and learners by embedding them in real-world contexts. In education, games are mostly used to motivate students and to increase their participation (Mitchell and Savill-Smith, 2004). Locatory is a mobile multi-user game (Unger, 2005; Zielke, 2005) which implements a ubiquitous version of a memory game in which two competing teams, each consisting of two collaborating people, should find the tiles corresponding to each other and which are spread throughout an office environment. In Human Pacman (Cheok et al., 2004), the participants play the characters of several 
pacmen and ghosts, and have to collaborate to obtain virtual cookies or capture pacmen, respectively. Environmental Detectives (Klopfer et al., 2002) is an example of an educational game that lets groups of students investigate a simulated pollution scenario by combining real-world and virtual data.

\subsection{Information flow - classifies applications according to the number of entities in the systems information flow}

The information flow between users and other entities within a social software system is described by several parameters. Johansen (1988) portrays a groupware software typology that makes a distinction between two values of place (same, different) and time (same, different). By combining different values of place and time, different ways of interacting and hence different kinds of systems can be analysed. When, for instance, both place and time are the same, a face-to-face meeting as a way of interaction suffices. However, the interaction between people is synchronous and distributed when they meet at the same time, but are not located at the same place; an interaction pattern that, for example, appears in videoconferences. Earlier in the paper the contextual parameters of individuality, locations, time, environment/activity and relations context were mentioned. The influences of place and time can be perfectly modelled by using at least two of these contextual parameters, location and time, and therefore will not be considered here.

Another aspect governing the information flow is the relationships between users and other entities in the system. The relationships can be described using a ratio relating the number of users or entities on either side. The ratio identifies the number of relationships possible. The following values are identified for the ratio describing the information flow: one-to-one, one-to-many, many-to-one and many-to-many.

An example of a one-to-one flow of information is the system in Liu and Kao (2005) that uses shared displays in a classroom to support collaborative learning. Also the social awareness systems that rely on serendipity to introduce familiar strangers to each other provide a one-to-one communication.

The information flow in classroom response systems, as for example Chen et al. (2005), is often many-to-one; the students in the classroom communicate with the teacher. However, classroom response systems provide the teacher with an awareness of problems students have and therefore are also aimed at providing better one-to-one relationships. For direct one-to-one communication in a classroom technical support is often not needed because it is mostly face-to-face. Related to a classroom response system is 'Ask the Author' (Deng et al., 2005), a conference system that supports people in a conference audience asking the author questions. The mobile system only provides a many-to-one information flow by allowing the audience to post questions to the author via their mobile devices; the author then can answer the question face-to-face, providing a one-to-many information flow.

Some systems integrate multiple information flows. C-Notes (Milrad et al., 2002), for example, integrates many-to-one (students to teacher), one-to-many (student adds interesting articles and notes to the system, readable for others as well) and many-tomany (content can be added by more students and viewed by more). 


\subsection{Pedagogical paradigms and instructional models}

Naismith et al. (2004) in their review of mobile learning identified several theory-based categories of activity that are relevant for the design of mobile learning: behaviourist, constructivist, situated, collaborative, informal and lifelong, and learning and teaching support. Mainly in the classification, we will focus on the different pedagogical paradigms of behaviourist, cognitive, constructivist and social constructivist approaches found in the literature. Collaborative learning support, however, is used throughout all mobile social software for learning considered in this review. Therefore, this subsection analyses the other pedagogical models that have been applied in combination with the collaborative one.

Behaviourist approaches on learning are the foundation of most notification systems. Notification systems often want the learner to respond in a certain way according to the notification. The stimulus of the notification leads to attention to a certain event in the learning process. For example, in Eagle and Pentland (2005) notifications are used to introduce people with similar interests to each other to highlight a learning opportunity. Moreover, the more standard form of notification systems (Berger et al., 2003; Silander et al., 2004; Liu et al., 2005) wants the user to react on or learn about some peer activity being performed.

Constructivist approaches like MediaBoard (Colley and Stead, 2004) create a mobile accessible working space aimed at fostering interaction in a community of practice (Wenger and Lave, 1991). Annotation tools like Mobile Notes (Bollen et al., 2006) used in brainstorming sessions are often also designed from a constructivist point of view.

An example of situated learning support is the RAFT project that aims 'to provide a cooperative learning environment spanning field trip and the classroom' (Hine et al., 2003). Likewise, Silander et al. (2004) combine situated learning in the form of a field trip with students available in a classroom. Similarly, Mattila and Fordel (2005) and Paredes et al. (2005) also discuss a system aimed at field trips combined with a classroom discussion about the results of the field trip afterwards.

Informal and lifelong learning approaches are encountered in some systems. QueryLens (Konomi, 2002) is an example of such a system, in which a community of interest develops around real-world content, in this case music. Another platform specifically aiming at lifelong learning support is KLeOS (Vavoula and Sharples, 2002) allowing users to structure their learning activities, resources and knowledge to support learning anything, anywhere, anytime.

Most examples of learning and teaching support considered in this review are to a large extent applied to formal learning. Chen et al. (2005) present a classroom response system that allows students to respond to questions asked by the teacher. Saito et al. (2005) assist teachers in basic administrative tasks, like monitoring students' attendance, but also fosters collaboration between students.

\section{A reference model for mobile social software for learning}

The previous subsection identified the dimensions of a reference model for mobile social software for learning. Moreover, for each dimension a range of possible values has been identified. The reference model has been used to classify already existing applications of mobile social software for learning. However, it can also be used as a basis for future 
applications. For example: an already existing social software system can be analysed and extended to a context-aware one, using this model. An overview of the reference model for mobile social software has been shown in Table 1, which combines each of the identified dimensions with its possible values.

Table 1 A reference model for mobile social software for learning

\begin{tabular}{lllll}
\hline Content & Context & Purpose & Information flow & $\begin{array}{l}\text { Pedagogical } \\
\text { model }\end{array}$ \\
\hline Annotations & $\begin{array}{l}\text { Individuality } \\
\text { context }\end{array}$ & $\begin{array}{l}\text { Sharing content and } \\
\text { knowledge }\end{array}$ & One-to-one & Behaviourist \\
Documents & Time context & $\begin{array}{l}\text { Facilitate discussion } \\
\text { and brainstorming }\end{array}$ & One-to-many & Cognitive \\
Messages & Locations context & $\begin{array}{l}\text { Social awareness } \\
\text { Notifications }\end{array}$ & Many-to-one & Constructivist \\
& $\begin{array}{l}\text { Environment or } \\
\text { activity context } \\
\text { Relations context }\end{array}$ & $\begin{array}{l}\text { Engagement and } \\
\text { immersion }\end{array}$ & & $\begin{array}{l}\text { Social } \\
\text { constructivist }\end{array}$ \\
& & & & \\
\hline
\end{tabular}

Figure 1 shows a graphical representation of the reference model that gives an overview of how all concepts in the reference model are related. This is illustrated with an example application of a location-based document sharing. In the artefact layer, the different content considered is shown for the example application a user connects a physical object (1) with a document (2) and defines the connecting context (1). Furthermore, he specifies a location trigger for notifying other users (3) when they interact with the physical object.

Figure 1 A graphical representation of a reference model for mobile social software for learning

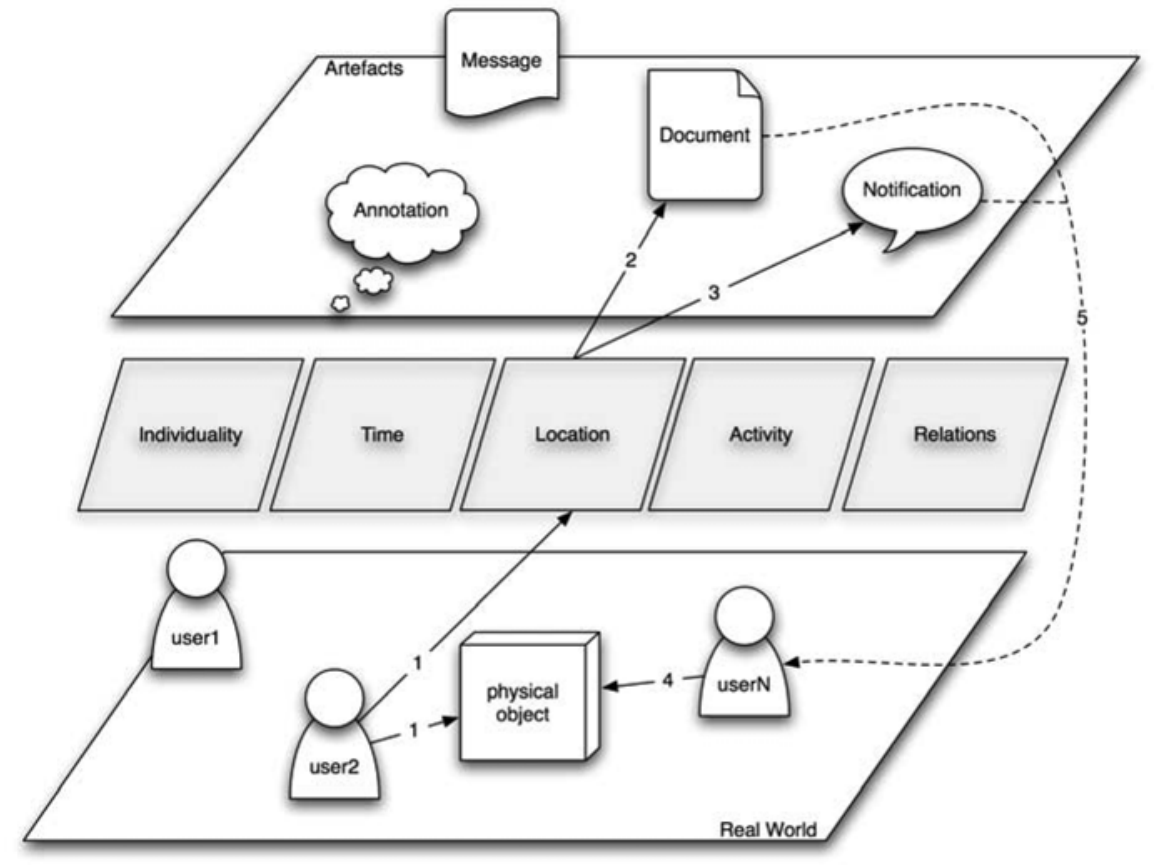


If other users interact with the object, notifications (4) and a document sharing process will be triggered (4). The reference model includes all necessary means to describe the content, context, and relationships included, and also gives a framework for the instructional models based on different pedagogical paradigms.

\section{Summary: trends in current state-of-the-art}

In the preceding sections, the current state-of-the-art for each dimension of the reference model was described. In this section, a summary of the trends for each dimension will be given as a basis for the analysis of the limitations in the next section.

The wide range of systems aimed at sharing content and knowledge has its impact on the dimension that considered the types of content available in mobile social software. Most of the mobile social software supports some kind of content sharing. Two categories of systems using content can be distinguished. The first are systems in which the sharing of some kind of multimedia information is the main focus of attention. Conversely, the second are systems which annotate some other content or are aimed at creating notes; the notes are not the main focus of the learner but rather are used to support learning by organising the learning process. Communication features offered by current mobile social software range from direct voice communication, instant messaging to leaving some kind of text message on a shared space. Communication technology is not the main consideration of a lot of research, but rather is seen as an extension to other systems. The main reason would be that the most popular devices, mobile phones, already offer outstanding communication capabilities. Surprisingly, the use of metadata and notifications was also not found extensively. Content metadata, specifying some extra information about the content stored, has been found in some cases. Most metadata found, however, specified a particular context; most often metadata used to describe location context was found. Notifications were mostly encountered in the form of SMS messages that were sent about a change in a shared context: someone in the group edited shared content or a person was added to the user's community. On the contrary, personalised messages focusing on making the user aware about interesting content in his vicinity were not found very often.

The second dimension analysed was the kind of context filter used. The most widely applied form of context filters was a location filter that adapts the learning content to the user location. Also social context information has been put to use in the social awareness systems more than the remaining context parameters; social context is for example used to derive relationships between people. There are a number of systems providing personalisation through identity context, a system using calendar information (time context) and some using environment context in the form of tagged real-world objects. Unfortunately, most of the other context parameters have not been commonly applied. In that sense, especially, the software systems that use simpler context parameters like location and time and use them to derive more complex context information, for example social awareness information, are in our opinion most interesting.

The third dimension considered was the purpose of the system. In the mobile social software research considered throughout the review, the systems aimed at sharing content and knowledge were mostly encountered. The content and knowledge sharing systems were closely followed by social awareness systems, which judging from the references have become more popular in the last years. Functionality that guides communication 
often has been combined with other system functionalities and rarely seems the major aim of a system. However, especially social awareness systems focus on improving or enkindling face-to-face conversations, which is the implicit aim of a lot of mobile social software we have analysed. Mobile collaborative games, specifically aimed at learning, were not encountered that much.

The cardinality of the information flows in mobile social software was given by the fourth dimension. The one-to-one collaborative systems found were either intended for peer-feedback, or for bringing people into contact with each other; social awareness. Moreover, the direct communication flows possible in some systems are often one-toone. Many-to-one or one-to-many relations are often seen in formal learning scenarios. Classroom response systems, for instance, are many-to-one; the students can respond to their teacher. More informal approaches, for example shared content repositories, often integrate several information and communication flows.

Fifth and the last, the pedagogical model used as a basis for the system was considered. Previously, the great availability of learning solutions aiming at content was already discussed. Most of these systems are based on a constructivist pedagogy, which is therefore also widely available throughout mobile social software for learning. Next to constructivist pedagogies, situated pedagogies are more widely encountered in the research considered, especially in the software systems that use a form of adaptation to the location of the user. Systems for learner and teacher support are also widely available, but with a focus at formal learning in the classroom. Finally, the behaviourist and informal and lifelong pedagogies are less available.

The summary of the current state-of-the-art presented in this section already hints at possible limitations in mobile social software for learning. The next section will describe the limitations more clearly, as a basis for suggested improvements for current learning solutions.

\section{Limitations of current solutions}

During the review and classification of the software, there were already some limitations of the current solutions implicitly identified. An overview of the limitations we think are most important is given in this section, for each dimension of the reference model.

First of all, some limitations of the content dimension are identified. While a lot of the systems aimed at sharing various forms of multimedia documents were encountered, the use of metadata about those documents is not that widely found; most of the metadata stored relates to author information or location data about content. One possible explanation for this absence of metadata could be the large overhead of implementing a metadata storage and query system; especially this is true for the small systems that were mostly encountered in this review. Furthermore, the support for ubiquitous notification is not widely available, and mostly relates to some collaborative action performed by the learner's peers. Notification based on contextual information to minimise interruption has not been found during this review.

Second is the usage of context filters. Mobile social software for learning rarely uses other context information besides location and identity context. For ubiquitous learning support, the time, the environment of the learner and especially the activity a learner performs are important. Therefore, time, environment and activity context should be more considered in future research. Moreover, a combination of context parameters to 
derive more complex information about the learning situation has not been largely encountered.

Third, relating to the purpose dimension we feel that there is a lack of integrated solutions available. A system that provides content creation and delivery combined with social awareness systems for effective community building was not found in the literature considered.

Last, the pedagogical models that have been used mostly focus on constructivist and situated learning. In our opinion informal and lifelong pedagogies should be given more attention, especially since these are the forms of learning that take place anywhere, anyplace, anytime, i.e. mobile or ubiquitous learning.

\section{Suggested extensions for improved learning}

Based on the limitations identified in the previous section, suggested extensions for mobile social software for learning will be given in this section.

To begin with, a better and wider use of metadata information throughout the systems is suggested. The storage of metadata information makes it easier to find appropriate content for appropriate learning activities. For example, content stored along with context metadata in a specific learning episode can later be reused and found in similar learning situations. An evaluation of the efficiency of such approaches can be found in the literature on recommender and tutoring systems based on episodic memory approaches (Weber, 1996).

Also, notifications should be more widely used and tailored to a specific learning situation, above all not interrupting that situation by drawing most of the learner's attention to the notification itself. The kind of notification (Eagle and Pentland, 2005) provided is particularly interesting because it integrates a notification with proximity information and information from a personal interest profile. However, next to this integrated approach, we did not find further examples where for instance time context, relationship contexts and more parameters were combined to further filter notifications. Moreover, notifications could also be extended to draw attention to interesting places or current events in the vicinity of a mobile learner, based on a personal profile and located calendar information.

Likewise, a better and wider use of more complex context information is suggested. Particularly, the time and environment/activity context deserves more attention in our opinion. The environment and activity context is the subject of ubiquitous computing research (Weiser, 1991; Abowd and Mynatt, 2000), and in this sense mainly two aspects are interesting: first, attaching content to real-world objects and using these enriched objects as new shared content repositories capable of building new learning communities. Second, the use of ubiquitous software systems and context information to try to support the current activity of the learner.

Moreover, we suggest the implementation of systems integrating a range of social software functionalities. Especially, the combination of shared content repositories with a form of social distributed awareness could be used to build more active and aware learning communities.

Last, in our opinion more attention should be given to support informal and lifelong learning by using mobile social software approaches. Informal and lifelong learning is a learning that takes place anywhere, anyplace, anytime, and especially this kind of 
learning could benefit from mobile social software applications embedding the user in one or more communities of practice wherever and whenever. Especially, the integration of informal and formal learning approaches should be investigated, in the sense of lifelong learning that incorporates formal education with learning encountered in everyday life. We feel this integration can be already, to some extent, made possible by combining content injection, content delivery and social awareness (by notifications).

Summarising the following extensions to the current state-of-the-art are brought forward:

- $\quad$ provide more integrated systems with a range of functionality

- $\quad$ better and wider use of metadata

- $\quad$ more advanced and wider use of notification techniques

- an improved adaptation to the user's personal preferences and learning environment or situation by using more kinds of context information than location and identity alone, and use of techniques to derive more detailed or higher level context information by a combination of different context parameters

- more attention to systems aiming at informal and lifelong learning.

\subsection{A possible solution: 'ContextBlogger' blogging in the real world}

The suggested extensions to mobile social software inspired us to develop an integrated application of mobile social software for learning. We applied the reference model to one specific instance of social software: weblogs. Already, some weblogs offer the creation and display of blog entries via mobile devices (www.nokia.com/lifeblog). However, the analysis of those mobile weblogs with the reference model, identified a possible extension which led to the development of 'ContextBlogger'. The ContextBlogger mobile software couples information in a weblog to physical objects in the real world. The innovative part of the system is that it uses mobile social software and tries to form social communities by interacting with real-world objects that surround the users. To enrich the interaction with information from virtual social software communities, the real-world objects are equipped with tags to identify them.

A number of aspects of mobile social software are integrated in the software. First of all, multiple users can use their mobile devices to create and insert multimedia into the weblog or view the information added because every object preserves its own history. Second, a weblog has a social community surrounding it, with the additional possibilities for rating and annotation which facilitates community feedback on information provided and around a physical object. Concluding, through the flexible combination of tags, physical objects, and different filters on the blog content, several educational effects can be achieved:

- Multiple perspectives on real-world objects: by viewing the object's history, a certain category of blog entries, or using other filters people benefit through an indirect learning process (Efimova and Fiedler, 2004; Walker, 2005).

- Community-generated content connected to relevant real-world objects and locations: an example for the effect and importance of self-generated contents in a 
learning community is presented in Brandt et al. (2002) and Brandt and Hillgren (2003) about learning to operate medical devices.

- Moreover, search filters give different views about objects, based on personal preferences. Real-world objects can also be linked by software to create relations between those objects and to create a so-called 'internet of objects' (Mattern, 2004).

The effects of ContextBlogger on the learner will be the subject of future research. Similar to ContextBlogger, the uLearn system (Mitchell and Race, 2005) also uses location and orientation of a mobile phone to retrieve multimedia information suitable to a specific context. The location information is retrieved by scanning a visual code or semacode attached to objects in the environment. The rotation or orientation of the mobile phone determined, amongst others, the type of information retrieved from the database: either a description of the object or a picture. However, uLearn does not provide any collaborative features and is aimed at delivering content to an individual learner.

\section{Conclusion}

In this paper, a reference model for mobile social software for learning was described. The reference model consisted of five dimensions, being: purpose, content, context filter, information flow and pedagogical model. Current research was classified according to the reference model. The results of the classification suggest that most of the mobile social software for learning aim at providing a shared content or knowledge repository and provided storage for all kinds of multimedia information. Additionally, location and identity context was used most, and constructivist and situated pedagogic models form the foundation of most current software solutions. Based on the limitations of the current state-of-the-art in mobile social software the following improvements were suggested: creating integrated systems to address a range of different learning purposes, extending the use of metadata, improved use of notifications, and more use of context information, as well as the combination of several context parameters to derive more detailed information about a learner's current situation. Moreover, we hope to see more focus on systems for informal and lifelong learning. Last, an example of a possible extension for current mobile learning was given, in the form of the ContextBlogger software; an informal collaborative learning application that makes it possible to attach blog information to real-world objects.

In the future, we expect to extend the context blogger software to an integrated solution for mobile learning. At this moment, the ContextBlogger software already provides a shared content system in which learners can collaborate to create and edit content and view the contributions of their peers. Furthermore, ContextBlogger's ubiquitous component creates links between community-added content and real-world objects and situations. A challenge for future research would be adding social awareness in the form of ubiquitous notification support; the best timing and form of notifications has to be researched. Especially, the use of notifications to point out people and objects of interest deserves special attention. Moreover, we want to experiment with new forms of media creation and delivery. Finally, the use of more complex forms of context information derived from the five basic context parameters: individuality, locations, time, environment/activity, and social/relations context (which forms a challenge that future 
research should, we feel, certainly address). In addition, the use of social or relations context could provide us with mobile learning solutions that not only address a specific individual, but also address the social environment and relationships for improved learning. Only a combined approach taking into account multiple aspects of a learner's environment would make learning truly ubiquitous.

\section{Acknowledgements}

This paper is (partly) sponsored by the Metadata for Architectural Contents (MACE) project that is co-funded by the European Commission in the eContentPlus program (ECP 2005 EDU 038098 MACE).

\section{References}

Abowd, G.D. and Mynatt, E.D. (2000) 'Charting past, present, and future research in ubiquitous computing’, ACM Transactions on Computer-Human Interaction, Vol. 7, No. 1, pp.29-58.

Anderson, T. (2005) 'Distance learning - social software's killer ap?', Paper presented at The 17th Biennial Conference of the Open and Distance Learning Association of Australia, 9-11 November.

Arrigo, M., Gentile, M., Taibi, D., Chiappone, G. and Tegolo, D. (2004) 'mCLT: an application for collaborative learning on a mobile phone', Paper presented at the MLEARN 2004, Rome, Italy.

Bardram, J.E. and Hansen, T.R. (2004) 'The AWARE architecture: supporting context-mediated social awareness in mobile cooperation', Paper presented at the ACM Conference on Computer Supported Cooperative Work.

Berger, S., Mohr, R., Nösekabel, H. and Schäfer, K.J. (2003) 'Mobile collaboration tool for university education', Paper presented at the Proceedings of the 12th IEEE International Workshops on Enabling Technologies: Infrastructure for Collaborative Enterprises.

Bergin, D.A., Anderson, A.H., Molnar, T., Baumgartner, R., Mitchell, S., Korper, S., Curley, A. and Rottman, J. (2007) 'Providing remote accessible field trips (RAFT): an evaluation study', Computers in Human Behavior, Vol. 23, No. 1, pp.192-219.

Bo, G. (2002) MOBILEARN: Project final report [electronic version]. Available online at: http://www.mobilearn.org/download/results/public_deliverables/MOBIlearn_Final\%20Report. zip (accessed on 1 July).

Bollen, L., Juarez, G., Westermann, M. and Hoppe, H.U. (2006) 'PDAs as input devices in brainstorming and creative discussions', Paper presented at the Fourth IEEE International Workshop on Wireless, Mobile and Ubiquitous Technology in Education (WMTE '06).

Brandt, E., Björgvinsson, E., Hillgren, P-A., Bergqvist, V. and Emilson, M. (2002) 'PDA's, barcodes and video-films for continuous learning at an Intensive Care Unit', Paper presented at the NordiCHI, 19-23 October, Aarhus, Denmark.

Brandt, E. and Hillgren, P-A. (2003) 'Self-produced video to augment peer-to-peer learning', Paper presented at the MLEARN 2003, 19-20 May, London, UK.

Bull, S., Bridgefoot, L., Corlett, D., Kiddie, P., Marianczak, T., Mistry, C., et al. (2004) 'Interactive logbook: the development of an application to enhance and facilitate collaborative working within groups in higher education', Paper presented at the MLEARN 2004, Rome, Italy.

Castells, M., Fernández-Ardèvol, M., Linchuan Qiu, J. and Sey, A. (2007) Mobile Communication and Society: A Global Perspective, MIT Press, Cambridge, MA. 
Chan, T., Corlett, D., Sharples, M., Ting, J. and Westmancott, O. (2005) 'Developing interactive logbook: a personal learning environment', Paper presented at the IEEE International Workshop on Wireless and Mobile Technologies in Education (WMTE '05).

Chen, Y-F., Liu, C-C., Yu, M-H., Chang, S-B., Lu, Y-C. and Chan, T-W. (2005) 'Elementary science classroom learning with wireless response devices-implementing active and experiential learning', Paper presented at the IEEE International Workshop on Wireless and Mobile Technologies in Education (WMTE '05).

Cheok, A.D., Goh, K.H., Liu, W., Farbiz, F., Fong, S.W., Teo, S.L., et al. (2004) 'Human Pacman: a mobile, wide-area entertainment system based on physical, social, and ubiquitous computing', Personal and Ubiquitous Computing, Vol. 8, No. 2, pp.71-81.

Cockburn, A.J.G. and Thimbleby, H. (1991) 'A reflexive perspective of CSCW', ACM SIGCHI Bulletin, Vol. 23, No. 3, pp.63-68.

Colley, J. and Stead, G. (2004) 'Mobile learning = collaboration', Paper presented at the MLEARN 2004, Rome, Italy.

Deng, Y-C., Chang, H-Z., Chang, B., Liao, H-C., Chiang, M-C. and Chan, T-W. (2005) ““Ask the Author”: an academic conference supported system using wireless and mobile devices', Paper presented at the IEEE International Workshop on Wireless and Mobile Technologies in Education (WMTE '05).

Dey, A.K. and Abowd, G.D. (1999) Towards a Better Understanding of Context and ContextAwareness (No. GIT-GVU-99-22): College of Computing, Georgia Institute of Technology.

Eagle, N. and Pentland, A. (2005) 'Social serendipity: mobilizing social software’, Paper presented at the Pervasive Computing, IEEE, April.

Efimova, L. and Fiedler, S. (2004) 'Learning webs: learning in weblog networks', Paper presented at the Web-based Communities, 24-26 March 2006, Lisbon, Portugal.

El-Bishouty, M.M., Ogata, H. and Yano, Y. (2006) 'Learner-space knowledge awareness map in computer supported ubiquitous learning', Paper presented at the Fourth IEEE International Workshop on Wireless, Mobile and Ubiquitous Technology in Education (WMTE '06).

Farnham, S., Kelly, S.U., Portnoy, W. and Schwartz, J.L.K. (2004) 'Wallop: designing social software for co-located social networks', Paper presented at the 37th Annual Hawaii International Conference on System Sciences, 2004, Hawaii.

Ferscha, A., Beer, W. and Narzt, W. (2001) 'Location awareness in community wireless LANs', Paper presented at the Informatik 2001, September, Vienna, Austria.

Green, H. and Hannon, C. (2007) Their Space: Education for a Digital Generation, Demos, London.

Greif, I. and Sarin, S. (1986) Data sharing in group work. Proceedings of the First Conference on Computer-Supported Cooperative Work, ACM Press, New York, pp.175-183.

Gross, T. and Specht, M. (2001) 'Awareness in context-aware information systems', Paper presented at the Proceedings of the Mensch und Computer - 1, Fachübergreifende Konferenz, Bad Honnef, Germany.

Grudin, J. (1994) 'CSCW: history and focus’, Computer, Vol. 27, No. 5, pp.19-26.

Hine, N., Rentoul, R. and Specht, M. (2003) 'Collaboration and roles in remote field trips', Paper presented at the MLEARN 2003, London, UK.

Houser, C. and Thornton, P. (2005) 'Poodle: a course-management system for mobile phones', Paper presented at the IEEE International Workshop on Wireless and Mobile Technologies in Education (WMTE '05), 19-20 May.

Jansen, M., Rossmanith, P., Uzun, I. and Hoppe, U. (2005) 'Integrating heterogeneous personal devices with public display-based information services', Paper presented at the IEEE International Workshop on Wireless and Mobile Technologies in Education (WMTE '05).

Johansen, R. (1988) GroupWare: Computer Support for Business Teams, The Free Press, New York, NY. 
Joseph, S., Binsted, K. and Suthers, D. (2005) 'PhotoStudy: vocabulary learning and collaboration on fixed and mobile devices', IEEE International Workshop on Wireless and Mobile Technologies in Education (WMTE 2005), pp.206-210.

Kajita, S. and Mase, K. (2006) 'uClassroom: expanding awareness in classroom to ubiquitous teaching and learning', Paper presented at the Fourth IEEE International Workshop on Wireless, Mobile and Ubiquitous Technology in Education (WMTE '06).

Ketamo, H. (2002) 'xTask-adaptable working environment', Paper presented at the IEEE International Workshop on Wireless and Mobile Technologies in Education (WMTE '02).

Klopfer, E., Squire, K. and Jenkins, H. (2002) 'Environmental detectives: PDAs as a window into a virtual simulated world', Paper presented at the IEEE International Workshop on Wireless and Mobile Technologies in Education (WMTE '02), August.

Knight, S. (2005) 'Innovative practise with e-Learning', Joint Information Systems Committee.

Konomi, S.I. (2002) 'QueryLens: beyond ID-based information access', Paper presented at the UbiComp 2002: Ubiquitous Computing: 4th International Conference, 29 September-1 October, Göteborg, Sweden.

Koper, R. (2005) TENCompetence: Building the European Network for Lifelong Competence Development (Project Draft), Open Universiteit Nederland, Heerlen.

Laso-Ballesteros, I. (2006) 'Research perspectives on collaborative infrastructures for collaborative work environments', Paper presented at the 15th IEEE International Workshops on Enabling Technologies: Infrastructure for Collaborative Enterprises (WETICE '06), June.

Liu, C.C. and Kao, L.C. (2005) 'Handheld devices with large shared display groupware: tools to facilitate group communication in one-to-one collaborative learning activities', IEEE International Workshop on Wireless and Mobile Technologies in Education (WMTE '05), pp.128-135.

Liu, C.C., Tao, S.Y., Nee, J.N., Liu, B.J., Chen, G.D., Hsu, C.C., et al. (2005) 'Supporting activity awareness for teams-games-tournaments with GSM Network', Paper presented at the IEEE International Workshop on Wireless and Mobile Technologies in Education (WMTE '05).

Lundin, J. and Magnusson, M. (2002) 'Walking and talking-sharing best practice', IEEE International Workshop on Wireless and Mobile Technologies in Education (WMTE '02), pp.71-79.

Mattern, F. (2004, November 2004) 'Wireless future: ubiquitous computing', Paper presented at the Wireless Congress, Munich, Germany.

Mattila, P. and Fordel, T. (2005) 'MOOP - Using m-learning environment in primary schools', Paper presented at the MLEARN 2005, Cape Town, South Africa.

Messeguer, R., Navarro, L. and Reyes, A. (2006) 'Group-awareness for mobile cooperative learning', Paper presented at the Fourth IEEE International Workshop on Wireless, Mobile and Ubiquitous Technology in Education - (WMTE '06), November.

Miller, B.N., Albert, I., Lam, S.K., Konstan, J.A. and Riedl, J. (2003) 'MovieLens unplugged: experiences with a recommender system on four mobile devices', Paper presented at the HCI 2003, Bath, England.

Milrad, M., Perez, J. and Hoppe, U. (2002) 'C-notes: designing a mobile and wireless application to support collaborative knowledge building', Paper presented at the IEEE International Workshop on Wireless and Mobile Technologies in Education (WMTE '02), August.

Mitchell, A. and Savill-Smith, C. (2004) The Use of Computer and Video Games for Learning, Learning and Skills Development Agency, London.

Mitchell, K. and Race, N.J.P. (2005) 'uLearn: facilitating ubiquitous learning through camera equipped mobile phones', Paper presented at the IEEE International Workshop on Wireless and Mobile Technologies in Education (WMTE '05).

Mitchell, K., Race, N.J.P., McCaffery, D., Bryson, M. and Cai, Z. (2006) 'Unified and personalized messaging to support E-learning', Paper presented at the Fourth IEEE International Workshop on Wireless, Mobile and Ubiquitous Technology in Education (WMTE '06). 
Naismith, L., Lonsdale, P., Vavoula, G. and Sharples, M. (2004) Literature Review in Mobile Technologies and Learning (Literature Review No. 11), University of Birmingham, Birmingham.

Ng'ambi, D. (2005) 'Mobile Dynamic Frequently Asked Questions (DFAQ) for Student and Learning Support', Paper presented at the MLEARN 2005, Cape Town, South Africa.

Nova, N., Girardin, F. and Dillenbourg, P. (2005, November) “"Location is not enough!”: an empirical study of location-awareness in mobile collaboration', Paper presented at the IEEE International Workshop on Wireless and Mobile Technologies in Education (WMTE '05), Tokushima, Japan.

Ogata, H. and Yano, Y. (2004a) 'Context-aware support for computer-supported ubiquitous learning', The 2nd IEEE International Workshop on Wireless and Mobile Technologies in Education (WMTE '04), pp.27-34.

Ogata, H. and Yano, Y. (2004b) 'Knowledge awareness map for computer-supported ubiquitous language-learning', Paper presented at the 2nd IEEE International Workshop on Wireless and Mobile Technologies in Education (WMTE '04).

Oppermann, R. and Specht, M. (2000) 'A context-sensitive nomadic exhibition guide', Paper presented at the Proceedings of the Second Symposium on Handheld and Ubiquitous Computing, Bristol, UK.

Oravec, J. (2002) 'Bookmarking the world: weblog applications in education', Journal of Adolescent and Adult Literacy, Vol. 45, No. 7, pp.616-621.

Paredes, R.G.J., Ogata, H., Saito, N.A., Yin, C., Yano, Y., Oishi, Y., et al. (2005) 'LOCH: supporting informal language learning outside the classroom with handhelds', Paper presented at the IEEE International Workshop on Wireless and Mobile Technologies in Education (WMTE '05).

RAMBLE Project (2006) Remote authoring of mobile blogs for learning environments. Available online at: http://ramble.oucs.ox.ac.uk/index.html (accessed on 14 November 2006).

Raymond, D., Mauad, C.E., Baudin-Thomas, V., Gayraud, T., Kanenishi, K., Matsuura, K., et al. (2005). 'Bringing mobility to synchronous collaborative activities: recent enhancements of the "Platine" platform', Paper presented at the IEEE International Workshop on Wireless and Mobile Technologies in Education (WMTE '05).

Rheingold, H. (2002) Smart Mobs: The Next Social Revolution, Perseus Books Group, Cambridge, MA.

Richter, A. and Koch, M. (2007) Social Software - Status quo und Zukunft (Technischer Bericht,Nr. 2007-01) [Social Software - Status quo and future (Technical report, Nr. 2007-01)], Fakultät für Informatik, Universität der Bundeswehr München, Munich, Germany. Available online at: http://www.unibw.de/wow5_3/forschung/social_software/ socialsoftwarefeb07.

Riordan, B. and Traxler, J. (2005) 'The use of targeted bulk SMS texting to enhance student support, inclusion and retention', Paper presented at the IEEE International Workshop on Wireless and Mobile Technologies in Education (WMTE '05).

Saito, N.A., Ogata, H., Paredes, R.G.J., Yano, Y. and San Martin, G.A. (2005) 'Supporting classroom activities with the BSUL environment', Paper presented at the IEEE International Workshop on Wireless and Mobile Technologies in Education (WMTE '05).

Schön, D.A. (1983) The Reflective Practitioner: How Professionals Think in Action, Maurice Temple Smith, London.

Schön, D.A. (1987) Educating the Reflective Practitioner, Jossey-Bass, San Francisco, CA.

Sharples, M., Corlett, D. and Westmancott, O. (2002) 'The design and implementation of a mobile learning resource', Personal and Ubiquitous Computing, Vol. 6, No. 3, pp.220-234.

Sharples, M., Taylor, J. and Vavoula, G. (2007) 'A theory of learning for the mobile age', in Andrews, R. and Haythornthwaite, C. (Eds.): The Handbook of E-learning Research. Sage, London, pp.221-247. 
Silander, P., Sutinen, E. and Tarhio, J. (2004) 'Mobile collaborative concept mapping-combining classroom activity with simultaneous field exploration', Paper presented at the 2nd IEEE International Workshop on Wireless and Mobile Technologies in Education (WMTE '04).

Smordal, O., Gregory, J. and Langseth, K.J. (2002) PDAs in medical education and practice. Proceedings of the IEEE International Workshop on Wireless and Mobile Technologies in Education (WMTE '02), pp.140-146.

Specht, M. (2006) 'Contextualized learning', in Chen, S.Y. and Magoulas G.D. (Eds.): Advances in Web-based Education: Personalized Learning Environments, IDEA Publishing Group, Hershey, PA.

Specht, M. and Kravcik, M. (2006) 'Authoring of learning objects in context', International Journal on E-Learning, Vol. 5, No. 1, pp.25-33.

Stead, G. (2005) 'Moving mobile into the mainstream', Paper presented at the MLEARN 2005, Cape Town, South Africa.

Tatar, D., Roschelle, D., Vahey, P. and Penuel, W.R. (2003) 'Handhelds go to school: lessons learned', IEEE Computer, Vol. 36, No. 9, pp.30-37.

Unger, M. (2005) Entwicklung eines kontextbasierten mobilen Spiels auf der Basis von macromedia flash [Development of a context-based mobile game based on macromedia flash], Fraunhofer Institut für Angewandte Informationstechnik (FIT), FH Offenburg.

Vavoula, G.N. and Sharples, M. (2002) 'KLeOS: a personal, mobile, knowledge and learning organisation system', Paper presented at the IEEE International Workshop on Wireless and Mobile Technologies (WMTE '02).

Walker, J. (2005) 'Weblogs: learning in public’, On the Horizon, Vol. 13, No. 2, pp.112-118.

Weber, G. (1996) ‘Episodic learner modeling’, Cognitive Science, Vol. 20, No. 2, pp.195-236.

Weiser, M. (1991) 'The computer for the 21st Century', Scientific American, Vol. 3, No. 265, pp.94-104.

Wenger, E. and Lave, J. (1991) Situated Learning: Legitimate Peripheral Participation, Cambridge University Press, Cambridge, NY.

Yatani, K., Sugimoto, M. and Kusunoki, F. (2004) 'Musex: a system for supporting children's collaborative learning in a museum with PDAs', Paper presented at the 2nd IEEE International Workshop on Wireless and Mobile Technologies in Education (WMTE '04).

Zielke, L. (2005) Entwicklung und Evaluation eines kontextbasierten mobilen Spiels unter Einbeziehung verschiedener Lokalisierungsverfahren, Unpublished Master, Fachhochschule Oldenburg, Wilhelmshaven.

Zimmermann, A., Lorenz, A. and Oppermann, R. (2007) 'An operational definition of context', Paper presented at Sixth International and Interdisciplinary Conference on Modeling and Using Context - The Context 07, 20-24 August, Denmark.

Zimmermann, A., Lorenz, A. and Specht, M. (2005a) 'Personalization and context-management', User Modeling and User Adaptive Interaction (UMUAI), Special Issue on User Modeling in Ubiquitous Computing, Vol. 15, No. 3-4, pp.275-302.

Zimmermann, A., Specht, M. and Lorenz, A. (2005b) 'Personalization and context management', User Modeling and User-Adapted Interaction, Vol. 15, pp.275-302. 